\title{
Últimos pronunciamientos jurisprudenciales en materia de responsabilidad patrimonial de interés para las Entidades locales
}

\author{
Carlos Romero Rey \\ Letrado del Tribunal Supremo
}

Uno de los temas que tradicionalmente ha suscitado mayor interés y, a la vez, mayor preocupación a las Entidades locales, ha sido y sigue siendo el tema de la responsabilidad patrimonial. En el presente análisis, vamos a hacer referencia a determinadas sentencias y resoluciones, tanto del Tribunal Supremo como de otros Órganos jurisdiccionales, todas ellas con un indudable interés o una indudable actualidad en la materia de la responsabilidad administrativa; si bien, con la necesaria reserva derivada del hecho de que algunas de las sentencias que comentaremos han sido objeto de recurso, por lo que no constituyen todavía, en algunos casos, resoluciones firmes.

Con carácter previo a nuestro análisis y teniendo en cuenta la enorme importancia que tradicionalmente ha venido teniendo la jurisprudencia del Tribunal Supremo para las Entidades locales, no podemos resistirnos a hacer una somera referencia a una cuestión que, a nuestro juicio, puede resultar perjudicial para el correcto funcionamiento de nuestras Corporaciones locales, cual es la restricción en cuanto al acceso por parte de las mismas al Tribunal Supremo.

Como todos saben, tras la reforma operada en la Ley de la Jurisdicción Contencioso-Administrativa por parte de la Ley Orgánica 19/2003, de 23 de diciembre, los Juzgados de lo Contencioso-Administrativo van a conocer de todos los recursos que se interpongan frente a los actos de la Administración local (lo que incluye las resoluciones que pongan fin a los procedimientos en materia de responsabilidad patrimonial) a excepción de las impugnaciones de cualquier clase de instrumentos de planeamiento urbanístico, excepción a la que ha de añadirse cualesquiera otra disposición de carácter general, que se atribuirán a la correspondiente Sala de lo Contencioso-Administrativo del Tribunal Superior de Justicia.

Esta reforma puede tener consecuencias muy positivas en términos de una mayor rapidez en cuanto a la resolución de los recursos, un procedimiento más ágil, que en un buen número de ocasiones se tramitará conforme al procedimiento abreviado, con concentración de trámites en el acto de la vista, que se va a practicar bajo los principios de oralidad e inmediación.

Ahora bien, la contrapartida negativa va a ser que el grueso de la actividad de la Administración local — con las excepciones a las que antes nos hemos referido- queda sustraída de la posibilidad de recurso de casación o de ca- 
sación para la unificación de doctrina. Ello es así porque tales recursos, por lo que a nosotros ahora nos interesa, de acuerdo con los artículos 86.1 y 96.1 de la Ley de la Jurisdicción Contencioso-Administrativa, únicamente pueden interponerse contra las sentencias dictadas en única instancia por las Salas de lo Contencioso-Administrativo de los Tribunales Superiores de Justicia.

Si a ello unimos el limitado alcance del recurso de casación en interés de Ley (artículo 100 de la Ley Jurisdiccional), esta restricción de la actividad de las Corporaciones locales en cuanto a la posibilidad de acceso a la casación, hemos de valorarla muy negativamente, al excluirse la parte sustancial de la actividad de las Corporaciones locales de la posibilidad del recurso de casación y, por tanto, de la función nomofiláctica y uniformadora que a través del mismo lleva a cabo el Tribunal Supremo en defensa del ordenamiento jurídico y de su correcta interpretación.

Si tenemos en cuenta que una buena parte de la normativa que rige a nuestras Entidades locales viene constituida por normativa básica estatal, que pueden existir hasta un total de 17 interpretaciones jurídicas diferentes de tal normativa y que no va a existir un órgano supremo que pueda llevar a cabo una labor uniformadora o resolver las posibles divergencias que puedan existir entre unas y otras interpretaciones, esta situación no sólo nos parece digna de lamentar sino igualmente generadora de una peligrosa inseguridad jurídica en un ámbito, el de la Administración local, donde precisamente es más necesaria la existencia de mayores dosis de seguridad jurídica.

Lo anterior dota de particular importancia a las sentencias que dicte en materia de responsabilidad patrimonial de las Entidades locales el Tribunal Supremo, porque de acuerdo con la configuración del recurso de casación y de la casación para la unificación de doctrina van a ir progresivamente disminuyendo en número. Y si bien es cierto que el sistema de responsabilidad patrimonial va a ser común para todas las Administraciones públicas (artículo 149.1.18 a de la Constitución) y que su regulación sustancial va a ser estatal, ello no obsta para que la aplicación del mismo a las competencias ejercidas por los Entes locales admita peculiaridades dignas de consideración que precisarían de la función uniformadora del Tribunal Supremo a la que antes hemos aludido, especialmente en un momento como el actual y el que se avecina en el que el gran debate que se plantea en torno a la reforma de la Ley de Bases de Régimen Local gira en torno al régimen de las competencias locales.

Correlativamente se hace más necesario, si cabe, el conocimiento de las sentencias dictadas por las Salas de lo Contencioso-Administrativo de los Tribunales Superiores de Justicia que van a conocer, vía recurso de apelación, de la mayor parte de las cuestiones que inciden en el mundo local.

La primera Sentencia objeto de comentario procede precisamente de la Sala de lo Contencioso-Administrativo del Tribunal Superior de Justicia de Extremadura, Sentencia de 10 de junio de 2004. Esta sentencia nos pare- 
ÚLTIMOS PRONUNCIAMIENTOS JURISPRUDENCIALES...

ce digna de comentario a pesar de que ni siquiera se refiere a la Administración local, sino a la Autonómica, si bien, sus consideraciones podrían hacerse extensivas a aquélla. El tema decisivo que aborda, por muy sorprendente que resulte después de las múltiples reformas o actualizaciones en la materia, es el del orden jurisdiccional competente en la materia a la que hoy nos referimos.

Una de las cuestiones que mayor inseguridad jurídica ha proporcionado a nuestro sistema de responsabilidad patrimonial ha sido el hecho de que tradicionalmente los cuatro órdenes jurisdiccionales hayan venido conociendo de reclamaciones de responsabilidad patrimonial frente a la Administración. Con independencia de la preferencia del orden penal, la exclusividad a favor del orden contencioso-administrativo que el Legislador ha tratado de imponer ha chocado en no pocas ocasiones con interpretaciones judiciales que han relativizado esa exclusividad.

La última vuelta de tuerca en este tema, o mejor dicho, la penúltima, a la vista de las circunstancias, tuvo lugar con la Ley Orgánica 19/2003, de 23 de diciembre, que incorporó expresamente una mención a las aseguradoras de las Administraciones públicas a efectos de que pudieran ser llevadas, como codemandadas, al proceso contencioso-administrativo.

La Sentencia que comentamos aborda la reclamación dirigida frente a una Administración (en este caso, la autonómica, a la que se le atribuyen daños en su calidad de Administración con competencias en materia de aprovechamientos cinegéticos, que autorizó indebidamente, según se alegaba, una determinada montería), una serie de particulares (entre otros, los organizadores de la montería y el cazador autor del disparo que causó las lesiones al demandante) y la compañía aseguradora del citado cazador.

Pues bien, la citada Sentencia, después de analizar la reforma operada por la Ley Orgánica 19/2003, anteriormente comentada, entra a conocer de la posible responsabilidad patrimonial de la Administración, al tiempo que declara la incompetencia del orden contencioso-administrativo para conocer de la acción dirigida frente a los particulares y a la compañía aseguradora, remitiendo tal cuestión al orden civil, señalando, entre otras cuestiones, que «la Ley Orgánica 19/2003, de 23 de diciembre, ha previsto que las aseguradoras sean parte demandada dentro del proceso contencioso pero siempre que lo sean de las Administraciones públicas pero no en el caso de que lo fueran de un particular, como ocurre en el caso que examinamos, para las que el orden jurisdiccional contencioso-administrativo resulta incompetente».

El pronunciamiento, con independencia de la opinión que nos pueda merecer, resulta discutible en la medida en que separa la continencia de la causa y atribuye al orden contencioso-administrativo el conocimiento de la reclamación dirigida frente a la Administración y al orden civil el conocimiento de la reclamación dirigida frente a los particulares y sus compañías asegu- 
radoras, debiendo tenerse en cuenta, además, que la posible responsabilidad de unos y otros dimana de unos mismos hechos.

La generalización de este criterio podría dar lugar a una huida del orden contencioso-administrativo mediante el recurso de dirigir la acción frente a la aseguradora del particular y entendemos que puede resultar contradictoria la existencia de dos procesos judiciales distintos, ante diferentes órdenes jurisdiccionales, que enjuicien la responsabilidad derivada de unos mismos hechos.

La segunda resolución a la que nos vamos a referir es la Sentencia de la Sala Tercera del Tribunal Supremo (Sección Sexta) de 20 de enero de 2005 que va a enjuiciar de manera muy significativa un supuesto de responsabilidad patrimonial de un Ayuntamiento derivada de la anulación de una licencia, exonerando de dicha responsabilidad a la Entidad local demandada como consecuencia del comportamiento del perjudicado, que va a ser el que rompa la imputabilidad del daño a la Administración.

El supuesto en cuestión analiza los posibles daños y perjuicios derivados de la anulación de la licencia de obras y de la licencia de actividad para la extracción, trituración y clasificación de áridos en una cantera, al carecerse de la correspondiente autorización por parte de la Administración autonómica.

Señala la sentencia que «debe considerarse que fue exclusivamente la grave conducta negligente de los instantes de la licencia, al solicitar éstas, sabedores como eran de que no concurrían los presupuestos normativamente exigibles para su concesión, la que determinó que posteriormente las licencias (...) hubieran tenido que ser anuladas.

Es evidente que de negligencia grave debe reputarse la actuación de quien solicita una licencia de actividades para la apertura de la cantera a que nos hemos referido en suelo clasificado como suelo no urbanizable, sin tener la autorización de la Comisión de Urbanismo de Barcelona, que posteriormente fue denegada. Cuando menos debe concluirse que los solicitantes no adoptaron las «precauciones necesarias» y más cuando (...) no es en modo alguno creíble que los actores en su condición de ostentar la titularidad de un complejo empresarial dedicado precisamente a las actividades extractivas, ignorasen que sus peticiones de licencias de obras y de actividades carecían del necesario soporte legal, tanto en el momento de presentación de sus solicitudes, cuanto en el de la adopción de los acuerdos municipales, concediendo las mismas, pues ninguna duda hay de que precisamente por la actividad a la que se dedicaban tenían que ser sabedores de que el Ayuntamiento de Gelida no podía conceder la licencia de actividades, sin la autorización de la Comisión de Urbanismo de Barcelona, y pese a ello se aprovecharon de unas licencias cuya concesión sabían que no era procedente».

La sentencia, como observará el lector, es enormemente importante porque no aplica el mecanismo de la concurrencia de culpas para compensar o 
ÚLTIMOS PRONUNCIAMIENTOS JURISPRUDENCIALES...

moderar la cuantificación de la indemnización, sino que simple y llanamente atiende al comportamiento del perjudicado para eximir de responsabilidad a la Entidad local, sin que ello, no obstante, no haya merecido críticas por algún autor que abogaba en este caso por aplicar la moderación de la responsabilidad administrativa y no la exención total ${ }^{1}$.

La siguiente resolución a la que queremos hacer referencia es la que enjuició las responsabilidades derivadas de la tragedia del camping de Biescas. Se trata de la Sentencia de 21 de diciembre de 2005, de la Sección Primera de la Sala de lo Contencioso-Administrativo de la Audiencia Nacional. Dicha tragedia, que dio lugar al fallecimiento de 87 personas se produce como consecuencia de unas lluvias torrenciales que asolaron un camping que se había situado en una zona que resultó ser de alto riesgo dado su emplazamiento en el denominado «abanico aluvial de un barranco».

Esta sentencia condena solidariamente a la Diputación General de Aragón así como a la Confederación Hidrográfica del Ebro fijando un quantum indemnizatorio por fallecido, con alguna excepción, de 180.203,63 euros. La condena a la Confederación Hidrográfica se fundamenta en su competencia en materia de policía del cauce fluvial y si bien es cierto que la misma no autorizó formalmente la ocupación por el camping de la zona, consintió con actos posteriores y concluyentes su instalación y normal funcionamiento hasta la fecha misma en que ocurrieron los hechos. Por su parte, la condena a la Administración autonómica se basa en el hecho de haber otorgado la autorización turística para la apertura del camping, siendo decisiva, según la sentencia, su intervención para que el camping se ubicara en un monte que, además, era de utilidad pública.

No se condena, sin embargo, al Ayuntamiento en cuyo término municipal se asentaba el camping y que igualmente aparecía como demandado y ello a pesar de que la Corporación municipal había otorgado la licencia de obras, la licencia de apertura e igualmente era el propietario del monte donde se situó el camping. Razona la sentencia que la Entidad local no ha tenido una intervención, ya sea por acción u omisión, en la producción del suceso. En efecto, sus atribuciones legales de cara a la existencia del camping sólo se limitan a la concesión de las licencias de obras y de apertura, pero éstas carecen de virtualidad sin las otras autorizaciones previas y vinculantes que le corresponden a la Comunidad Autónoma. Por otro lado, aunque el monte donde se situó el camping era de su propiedad, al ser de utilidad pública, la autorización de su ocupación correspondía exclusivamente a la Diputación General de Aragón.

\footnotetext{
${ }^{1}$ B. F. MACERA, «Sobre la exceptio doli como factor de exoneración de la responsabilidad administrativa por anulación de licencias urbanísticas. Comentario a la Sentencia del Tribunal Supremo, Sala Tercera, Sección Sexta, de 20 de enero de 2005», Revista de Administración Pública, núm. 127, julio-septiembre 2005 , pp. 477 y ss.
} 
Se destaca asimismo por la Sentencia, y este dato nos parece especialmente significativo, que se trata de una Entidad local de reducidas dimensiones y con precarios medios a su alcance, por lo que no se le puede exigir, más cuando las Administraciones públicas competentes autorizaron o consintieron la apertura y funcionamiento del camping, que pudiera prever un hecho como el ocurrido.

Resulta relevante esta resolución porque, a diferencia de lo que ha ocurrido en muchos casos en los que se acude al fácil recurso de la condena solidaria a todas las Entidades que hayan intervenido de forma más o menos directa en la producción del daño, postura que fue duramente criticada por la doctrina ${ }^{2}$, la Audiencia Nacional en este caso va a llevar a cabo un análisis sobre la participación de cada una de las Administraciones implicadas, examinando la competencia de cada una de ellas, el interés público tutelado y la intensidad en su intervención; llegando a la conclusión finalmente de la exención de responsabilidad patrimonial del Ayuntamiento demandado.

Un capítulo obligado al hablar de la responsabilidad patrimonial de la Administración local es la derivada de daños producidos a causa o con ocasión de festejos populares y muy singularmente los que se producen con ocasión de festejos taurinos. La casuística en este ámbito es enorme y únicamente nos referiremos a algunos pronunciamientos que puedan ser de interés.

En primer lugar, nos vamos a referir a la Sentencia de la Sala de lo Contencioso-Administrativo (Sección Sexta) del Tribunal Supremo de 28 de octubre de 2004, que confirma la Sentencia dictada por la Sala de instancia que había otorgado una indemnización de 90.000 .000 de pesetas a una espectadora menor de edad que acudió acompañada junto a su madre a un festejo taurino de vaquillas celebrado con ocasión de las fiestas patronales de una localidad canaria. En este caso, antes de acabar el festejo taurino que se celebraba en una plaza de toros, madre e hija deciden abandonar dicha plaza para lo cual bajan de sus asientos a través de las escaleras que se habían dispuesto hasta una zona de seguridad que se encontraba separada de la zona de toreo a través de unos postes de madera verticales con una distancia de separación entre unos y otros variable.

En este caso ha de significarse que el Ayuntamiento había obtenido la correspondiente autorización administrativa para la celebración del espectáculo de vaquillas, a cuyo efecto acompañó, conforme se exige por la normativa correspondiente, certificado técnico acreditativo de las suficientes condiciones de seguridad y solidez con que cuentan las instalaciones. A pesar de ello, el Tribunal Supremo razona que «Es innegable que la organización de un festejo taurino lleva consigo no sólo la necesidad de solicitar y obtener - como así ocurrió - la correspondiente autorización (...) sino también el de-

\footnotetext{
${ }^{2} \mathrm{~S}$. MuÑoz Machado, La responsabilidad civil concurrente de las Administraciones Públicas (y otros estudios sobre responsabilidad), Civitas, $2^{\text {a }}$ edición, Madrid, 1998.
} 
ÚLTIMOS PRONUNCIAMIENTOS JURISPRUDENCIALES...

ber de comprobación y mantenimiento de las condiciones de seguridad que tales instalaciones han de tener. Y en el presente caso, es evidente que la valla de protección instalada para separar las zonas a que se ha hecho referencia no reunía las debidas condiciones de seguridad, en cuanto que la distancia existente entre los postes de madera permitió a la res pasar por entre ellos y acceder a dicha zona de seguridad, que servía de paso para el público asistente como espectador, desde el entarimado ya mencionado hasta la salida del recinto, con las consecuencias ya referidas, por lo que es clara en el presente caso la responsabilidad patrimonial del Ayuntamiento demandado».

Otra Resolución que ha citarse en este ámbito de los espectáculos taurinos es la Sentencia de la Sala de lo Civil del Tribunal Supremo de 29 de septiembre de 2005. En este caso y dentro de las fiestas de la localidad, se celebra en un municipio valenciano un encierro de reses bravas que concluye con la embestida y posterior fallecimiento de uno de los vecinos que participaron en dicho encierro. Ha de significarse que en este supuesto la autorización administrativa para la celebración del encierro no la solicita a la Comunidad Autónoma propiamente el Ayuntamiento sino una determinada peña taurina. La sentencia confirma la dictada por la Audiencia Provincial de Valencia que condena al pago de una determinada indemnización a la citada peña taurina así como a su aseguradora. Lo significativo del caso, por lo que a nosotros nos afecta, es que el Ayuntamiento queda eximido, ya desde la sentencia dictada en primera instancia, de toda responsabilidad.

La solución apuntada contrasta con un criterio uniforme mantenido por la jurisprudencia contencioso-administrativa (por todas, Sentencia del Tribunal Supremo de 19 de junio de 1998) según la cual, se deben integrar en el ámbito del funcionamiento de los servicios públicos las fiestas populares organizadas por los Ayuntamientos o patrocinadas por ellos, aun cuando la gestión de las mismas se haya realizado por comisiones o por entidades con personalidad independiente.

Vamos a referirnos, asimismo, a un principio cuyo estudio se ha puesto últimamente de moda en la doctrina, cual es el denominado principio de precaución y ponerlo en relación con la responsabilidad administrativa.

El principio de precaución cuya gestación se produjo primordialmente en el ámbito del Derecho comunitario y que desde ahí se ha ido recibiendo en los ordenamientos nacionales, generalmente a través de legislación sectorial de muy distinto signo, como medio ambiente, sanidad, telecomunicaciones, consumo, etc; puede resumirse diciendo que «no debe esperarse a tomar las medidas necesarias para evitar o prevenir un perjuicio grave e irreversible hasta que se disponga de una evidencia científica concluyente, ya que por aquel entonces, podría ser demasiado tarde» ${ }^{3}$.

\footnotetext{
${ }^{3}$ Vid. D. BerberofF, «Aspectos generales del principio de precaución y su incidencia en el ámbito local», Cuadernos de Derecho local, núm. 7, febrero de 2005, p. 143.
} 
La resolución a la que vamos a referirnos es a la Sentencia de la Sala de lo Contencioso-Administrativo (Sección Cuarta) de la Audiencia Nacional de 21 de julio de 2004, cuyo criterio ha tenido continuidad en otras Sentencias de la misma Sala, como la de 3 de noviembre de 2004. En este caso no se analiza una posible responsabilidad administrativa de una Entidad local sino del Ministerio de Sanidad y Consumo ante la aplicación por parte de dicho Ministerio del principio de precaución y de una determinada inmovilización de determinados productos alimenticios (una alerta alimentaria). No obstante, la aplicación de los criterios que se establecen a la Administración local resulta obligada si tenemos en cuenta, por ejemplo, que el control de alimentos y bebidas constituye un servicio obligatorio que todos los municipios, por sí o asociados, deberán prestar (artículo 26.1.a) de la Ley 7/1985, de 2 de abril, Reguladora de las Bases de Régimen Local).

Pues bien, la Sentencia de la Audiencia Nacional enjuicia la acción de responsabilidad patrimonial ejercitada por una determinada empresa que solicita la reparación de los daños y perjuicios derivados de una resolución del Ministerio de Sanidad y Consumo que inmovilizaba cautelar y transitoriamente cuantos productos se oferten al consumidor final bajo las denominaciones de aceite de orujo refinado y aceite de orujo de oliva, por considerar que dicha alerta alimentaria fue la causa del hundimiento generalizado del mercado del aceite de orujo.

Razona la sentencia que la alerta declarada tenía su fundamento jurídico en la legislación sectorial española en materia de sanidad y, por otro lado, que la misma resultaba justificada dada la presencia en dicho aceite de unos determinados hidrocarburos que pueden entrañar riesgos para la salud humana, tal y como había advertido la Organización Mundial de la Salud. La sentencia razona igualmente que la medida cumple los criterios de proporcionalidad y transitoriedad, criterios que resultan exigibles para la correcta aplicación del principio de precaución según viene propugnando la jurisprudencia comunitaria. Por lo tanto, la Sala concluye que los daños reclamados no constituyen una lesión antijurídica que la empresa reclamante no tenga el deber jurídico de soportar, al ajustarse la alerta declarada al marco de aplicación al que antes nos hemos referido.

Es decir, con independencia de que se hubiera acreditado un determinado daño efectivo y que se constatase la existencia de un nexo causal entre la actuación administrativa y el citado daño, la correcta utilización del principio de precaución, con arreglo a las exigencias de proporcionalidad y transitoriedad, evitan la antijuridicidad del daño, esto es, el particular necesariamente ha de soportar el citado daño.

En definitiva, es enorme la virtualidad del principio de precaución ${ }^{4}$ y su

\footnotetext{
${ }^{4}$ Uno de los intentos más logrados de poner en relación el principio de precaución y la responsabilidad administrativa, los límites y las interrelaciones entre ambas instituciones se encuentra contenido en
} 
ÚLTIMOS PRONUNCIAMIENTOS JURISPRUDENCIALES...

aplicabilidad a diversos ámbitos donde las Entidades locales ejercen sus competencias, no sólo el de salud pública, al que nos hemos referido, sino también medioambiental e incluso urbanístico, ante la necesidad de prever en el planeamiento correspondiente la incidencia que puedan tener determinados riesgos (naturales, pero no sólo naturales) respecto de un asentamiento urbano y de una población.

Para finalizar, es necesario llevar a cabo una somera reflexión al hilo de la multiplicación de reclamaciones de responsabilidad patrimonial que todas las Administraciones tienen que afrontar y singularmente las Entidades locales, precisamente, quizás por ser la Administración más cercana al ciudadano, reflexión que debemos al Prof. Martín Rebollo, que pone de manifiesto que la presencia de un Estado social entre nosotros y un generoso régimen de responsabilidad oculta en ocasiones una cuestión central desde el punto de vista de la actitud democrática y cívica: la cuestión de la responsabilidad individual ${ }^{5}$.

Es cierto que en buena parte de nuestra sociedad no ha calado aún la conciencia de lo público como algo propio, porque en vez de pensar «es de todos, luego es mío también», sustituimos ese pensamiento por una conclusión perversa: «no es mío, luego no importa».

En este sentido, consideramos, finalmente, que el principio de responsabilidad de la Administración (que no debe contemplarse únicamente como garantía para los ciudadanos, sino también como criterio rector de la actuación de las Administraciones públicas) ha de contribuir, incluso desde una perspectiva pedagógica, a la dignificación de lo público, a la toma en consideración de la responsabilidad individual de los ciudadanos y finalmente a la percepción de nuestro Estado social y de nuestro sistema de responsabilidad administrativa, no como un patrimonio solvente capaz de resarcirnos ante un daño en el que adivinemos la presencia, aunque sea difusa, de una Administración pública, sino como un instrumento de toda la sociedad al servicio de los intereses generales.

el informe anual que en el año 2005 el Consejo de Estado francés dedicó con carácter monográfico a la responsabilidad y a la socialización del riesgo. Rapport Public 2005. Jurisprudence et avis de 2004. Responsabilité et socialisation du risque, Conseil d'Etat, La Documentation Française, París, 2005, pp. 205 y ss.

${ }^{5}$ L. Martín Rebollo, La responsabilidad patrimonial de las Entidades locales, Iustel, Madrid, Madrid, 2005, pp. 10 y 11. 